\title{
Strategic Elements in the Implementation of ISO 9001:2000 Quality Management System in Universities and Manufacturing Organizations
}

Tom Bramorski, (E-mail: bramorst@uww.edu), University of Wisconsin-Whitewater Slawomir Zaplata, (E-mail: slawomir.zaplata@ae.poznan.pl), Poznan University of Economics

\begin{abstract}
In this paper we discuss strategic issues related to achieving ISO 9001: 2000 certification. We identify similarities and differences in implementing and maintaining ISO 9001:2000 quality management system in manufacturing and service organizations using the system development and implementation experiences of the authors from a meat processing plant and a College at a University.
\end{abstract}

\section{INTRODUCTION}

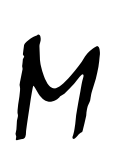

anufacturing, service and governmental organizations today often attempt to achieve a competitive advantage in the market by obtaining ISO 9001:2000 certifications of their processes. In some cases this approach generates a competitive advantage. However, there are many examples when achieving the certification has placed the certified organization at a strategic disadvantage. The purpose of this paper is to present strategic implications of achieving a sustainable competitive advantage utilizing the ISO 9000 certification. Using practical examples we discuss practical issues encountered in implementing and maintaining a quality management system. We conclude that while the requirements of ISO 9001: 2000 are generic an organization should customize them to best fit their needs rather than use template solutions.

\section{A Strategic Model for Quality System Improvement}

The experiences of the organizations presented in this paper indicate that there exists a need to develop a model integrating a variety of quality management tools and techniques. Such a model would be beneficial to managers working in the area of development and implementation of quality systems in organizations in a way consistent with the goals contained in the general strategy of the firm. This approach would help managers avoid seeking quick fixes to fundamental strategic problems facing their organizations. The improvements in the areas of process and product quality could then be better integrated with strategic goals. Such an approach would clearly improve overall organizational effectiveness.

The first step in the process should be the involve data collection from the market and conducting comprehensive benchmarking analysis in order to determine organizational strategic improvement areas that are most likely to maximize value to consumers. As shown in Figure 1, an arbitrary process level quantified by a metric, such as a percent of nonconforming items, has continuously declined for the world class company. This trend is consistent with the continuous improvement philosophy of TQM. We note that the selection of the area for improvement should be based on the analysis of relative importance of order-winning criteria. Maintaining focus of improvement efforts maximizes value to the consumers. We observe that competitors " $\mathrm{X}$ " and " $\mathrm{Y}$ " depicted in Figure 1 have improved their performance even more dramatically than the world class level and it can be expected that unless some drastic changes take place " $\mathrm{X}$ " may soon emerge as the world class leader. We also note that company " $Y$ " has a significantly better improvement growth rate relative to " $\mathrm{X}$ " while the performance of " $Z$ " has deteriorated. 
Let Cases 1 and 2 in Figure 1 represent hypothetical positions of a given organization against the competition. In Case 1 the size of the competitive gap is relatively small so that the gap can be closed with relatively modest resources in a reasonable amount of time. In Case 2 the size of the competitive gap is relatively large and significant structural changes should take place to close the gap separating the company from its competitors and the world class level. Naturally, the decision whether to close the gap or not is a strategic decision to be taken by top management. Broad organizational commitment and significant resources to be allocated to high priority areas are required in order for this process to succeed. We assume that it was determined that improving product/service quality was found to be a high strategic priority for the organization. Let TNOW in Figure 1 be the time when the organization must take strategic decisions regarding methods to improve product or service quality.

Figure 1: The present market analysis

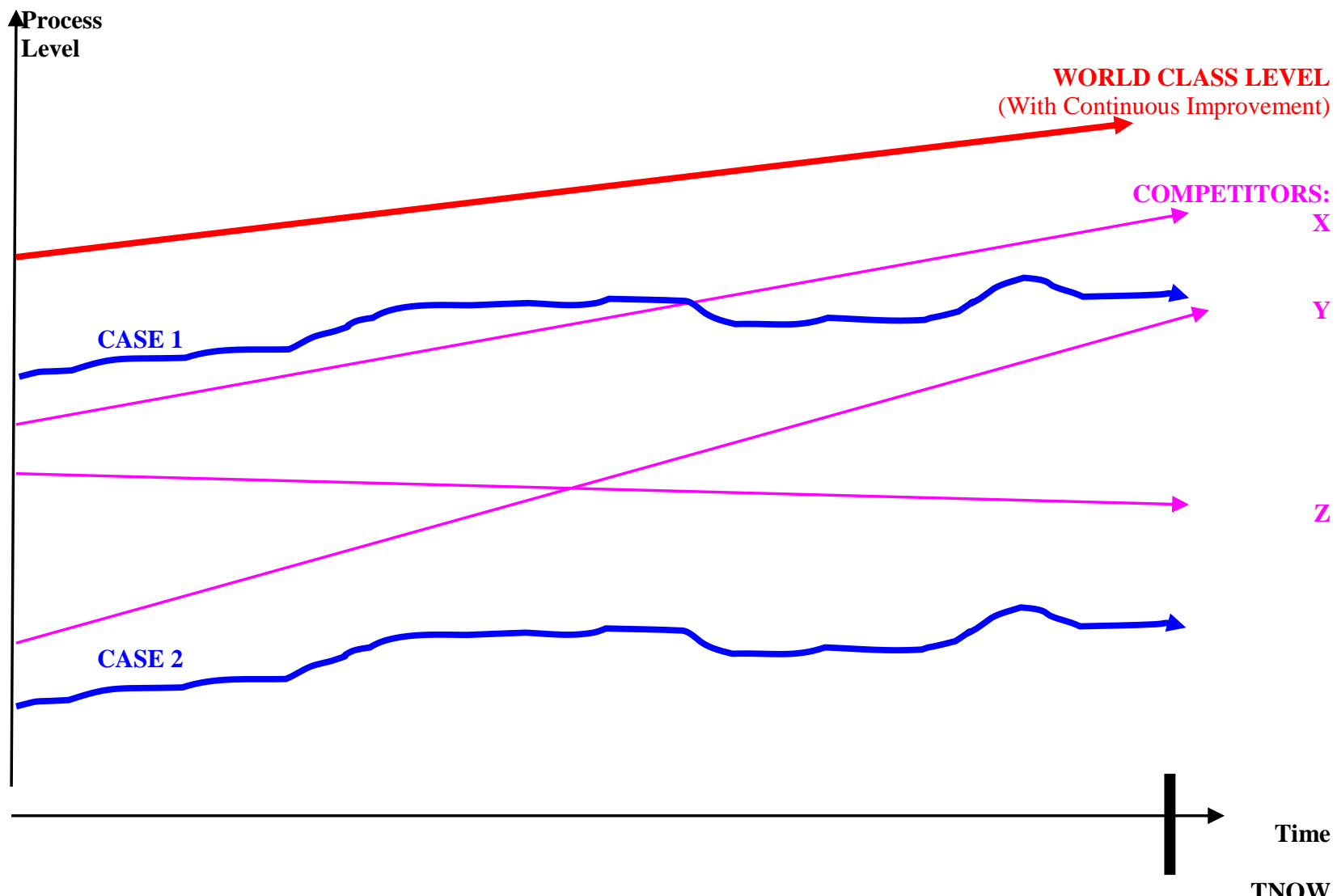

The second step toward improving product/service quality should involve the development of strategic initiatives in order to determine the amount of resources needed to achieve the desired future strategic position of the company in the market. Let us consider three scenarios shown in Figure 2 and labeled respectively "A", "B" and " $C$ " for Case 1 (small competitive gap), and "D", "E" and "F" for Case 2 (large competitive gap.) For scenarios "C" and "F" the company has determined not to improve its performance on quality dimensions likely due to a lack of necessary resources (time, money, etc.) This behavior is characteristic of a company that is mainly interested in maintaining a status quo. Hence, nothing needs to be done in order to improve its performance as any investment in process or product quality improvement, including quality system development and certification to ISO 9001: 2000, would mean inefficient use of available resources. Such improvement would not be consistent with the strategic direction of the organization. 
For scenarios "B" and "E", the company is strategically interested mainly in maintaining its present market position. Clearly, low-cost "maintenance" strategies should be designed and implemented in these cases. Finally, for scenarios "A" and "D", the company strategy calls for closing the magnitude of the competitive gap. Under scenario "A" this will quickly lead to its becoming the world class company without demanding large organizational resources. In case " $\mathrm{D}$ " the organizational transformation will likely be both costly and time consuming as major changes in business processes and technologies are required to accomplish the required strategic transformation.

Figure 2: The future strategic repositioning.

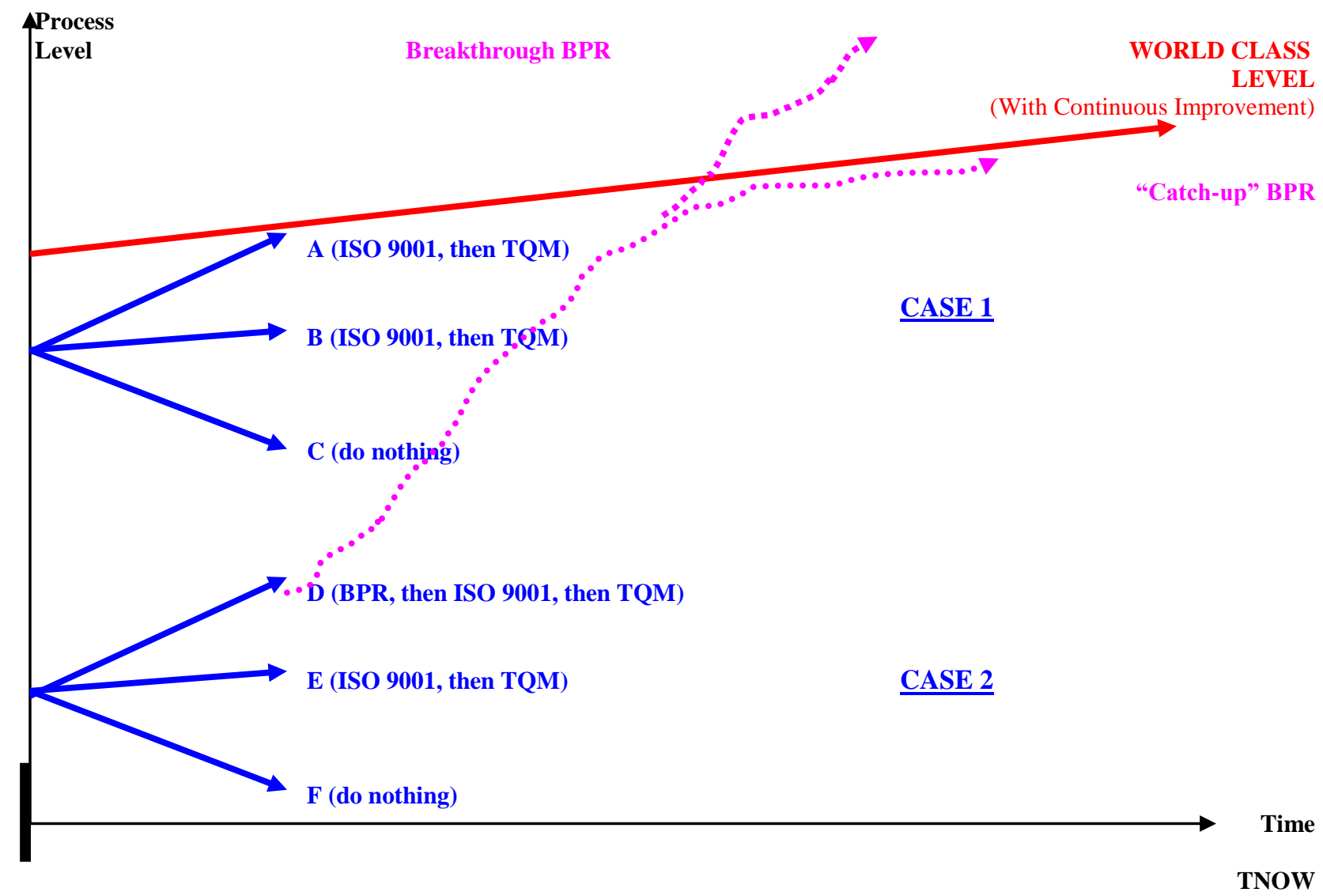

The third step toward improving product/service quality should involve the development of specific action plans that determine specific types of resources needed to implement the strategy developed in step two, the implementation schedule and the responsibilities. This process necessitates matching the strategic objectives with available and necessary organizational resources, and determining priorities. This methodology necessitates making periodic assessments of needs to match them with organizational resources and performing progress monitoring (gap analysis). When the necessary resources are not available or when reallocating them would put excessive strain on current operational organizational priorities, such as the need to meet production and delivery schedules, both the strategic needs and the resource allocations should be adjusted to bring about equilibrium. This should be done through an iterative process of strategy development and modification in response to the market dynamics. The gap analysis tool requires the development of data collection and analysis schemes to objectively assess progress in achieving strategic goals of the organization. 
The fourth step toward improving product/service quality should involve the development and deployment of appropriate policies necessary to achieve strategic targets in the area of process and product quality improvement As noted in Figure 2, under scenarios "C" and "F" there is no reason to commit any significant resources to develop and certify a quality system since doing so would be contrary to the selected strategy. For scenarios "A", "B", and "E" it is strategically appropriate to develop and certify a quality system according to ISO 9001: 2000 and then use the tools and techniques of TQM continuously over time to raise the level of appropriate process impacting product/service quality. This level of resource commitment and action sequencing are appropriate because the current position of the organization in the market and its future strategic plans are consistent.

We note that under scenario " $\mathrm{D}$ " achieving the quality system certification would be a strategic mistake. Due to the documentation development and verification effort involved, the ISO 9001: 2000 certification should be viewed as a strong "freezing" factor. Committing the organization to ISO 9001: 2000 certification effort is appropriate only when the current levels of processes are consistent with where they are supposed to be after all tradeoffs have been properly considered. In Figure 2, scenario ' $D$ ' illustrates a situation typical of businesses playing the catch-up game. Hence, the organization should first make changes to its processes necessary to bring quality to the desired level and then follow-up with system certification. It is intuitive to see that after ISO 9001: 2000 certification has been obtained making changes to processes will be significantly more difficult. First, a drastic change in the affected process should be implemented before "freezing" in the form of process certification is applied. Only minor modifications should be permitted to take place thereafter. Hence, the appropriate way to proceed under scenario " $D$ " is to first reengineer (i.e. "unfreeze") the affected process. The BPR approach will dramatically change the process level to one that is consistent with the strategic target, i.e. near the world class level. After the process has been "unfrozen", the use the ISO 9001: 2000 certification (i.e. "freezing") should be applied in order to internalize the changes. This should be followed by comprehensive employee training and the use of continuous improvement tools based on the concepts of TQM. This way the organization should appropriately solidify the desirable changes that were made through business process reengineering BPR and effective utilize the resources.

\section{Issues in ISO 9001:2000 Quality System Implementation}

The difficulties in implementing the ISO 9001: 2000 based quality system in food processing, service and government organizations were very similar. An initial reluctance of middle level management and employees to commit to the ISO 9001: 2000 system was observed. A major concern is that the project requires a significant effort on the part of everybody involved with little or no benefits to the individuals or teams involved. In addition, the strategic benefits of registration to the company and the individual employees and teams were not fully understood.

The food processing business has been in operation since 1983. It is a job shop that employs approximately 300 people and operates two shifts. There are several departments in the organizational structure including operations, accounting and sales. The scope of the quality management system is restricted to operations. The University of Economics consists of three colleges has been in business for over 75 years. The experiences reported in this paper concern exclusively the Commodity Science College of the University. The College consists of several departments and laboratory facilities that deals with a wide range of chemicals used in food preparation, processing, and preservation in a broad variety of environments. Examples of products include jams, cereals, fish, meat and dairy products. Storage environments include food warehouses (with and without temperature and humidity control), transportation and logistics, supermarkets, restaurants and marine (saline) storage applications.

Typically during the first year, approximately 1.5 years after the decision to obtain system certification was taken, the certification team has to educate management and key employees (specifically, the union representatives) about the complexities of simultaneously obtaining the certifications. A lack of in-depth understanding of these processes and the differences between them resulted in insufficient resources being allocated to the certification project which, in turn, produced both quality system team burnout and significant project delays. The reason for this was a low priority assigned to the certification project by management. High priority was traditionally given to meeting pending customer orders, which frequently resulted in certification-related work being put away indefinitely. After (an) external consultant(s) educated management on the strategic benefit, the philosophy and the structure of the certification program, getting the certifications had become a high priority strategic objective for the entire 
organization. More time, money and personnel resources were allocated to the project. The result was noticeable and steady project progress of the certification project.

During the second year, issues related to quality system were related primarily to overcoming employee fear and a general lack of understanding of the processes throughout the organization. Operational level employees were having difficulties relating their work to the certification requirements and understanding the role they were expected to play in the quality system. Another difficulty was broadening a definition of a customer to include one's colleague or friend in a way consistent with requirements as well as introducing the concepts of micro and macroprocesses. For example, operational level employees in a food processing organization had had difficulties understanding the theoretical concepts of an element of the quality system, which is concerned with the methodology of controlling products, parts, tools, packing materials and other resources originating with the customer. Whether these materials should be controlled at all was a topic of daily disputes amongst the employees. There were also significant disagreements between employees regarding how to handle this requirement effectively. The problem was addressed by offering training for the employees on the foundations of ISO-9001: 2000, SPC, and TQM where all such questions were discussed by both external and internal consultants. It should be noted that the training has been offered on an on-going basis and employees can have their questions and concerns answered by qualified experts in a low-pressure, informal setting of the training. Such a system has greatly increased the level of awareness of employees about the challenges presented by the certifications.

During the third year, the major focus was on formalizing and coordinating the program of continuous improvement (e.g. modifying documentation and designing customized training programs) as well as preparing for a series of internal and external quality audits preceding the certification. These commitments typically consumed significant blocks of time on the part of groups not involved in the certification process on a day to day basis. Hence, coordinating them with short-term operational goals (e.g. Just-in-Time deliveries of components to customers) became necessary and difficult. Several key people working in teams at critical time periods allowed the businesses meet both its short-term operational obligations and the certification requirements.

Surprisingly, after the ISO-9001: 2000 certification has been obtained and initial efforts have been made to incorporate elements of continuous improvement, there has been a significant drop in top management interest and commitment to continually changing the corporate culture. We note that the need to maintain constancy of purpose is one of the fundamental requirements of continuous improvement (TQM) and is also one of the foundations of ISO 9001: 2000. This development resulted in stalling the continuous improvement effort following the registration and ultimately to the departure of key individuals involved in the quality system certification project from the food processing organization.

The food processing plant and the University implemented the ISO 9001:2000 system in the following phases.

1. The decision to develop and implement the quality management system was taken by top management. This step involved evaluating strategic benefits derived from the system certification that accrued to the organization and the associated costs.

2. Preliminary identification of organizational processes to be documented and review of existing organizational rules and procedures were performed. The objective of this step was to assess the magnitude of the gap between current processes and ISO 9001: 2000: system requirements.

3. Detailed identification, definition and mapping of the processes (primary and supporting) in the organization that were identified in step (2) above were conducted. This created the foundation for determining the scope of the certification project.

4. Appropriate system documents (the quality manual, procedures, and instruction) were drafted, reviewed and approved. This step involved organization units, groups and individuals affected by the process being documented.

5. Final versions of these documents were distributed to organizational units for implementation.

6. Internal auditors were selected. The role of these individuals was to assist in the implementation of the system, conduct training and performing internal audits with the objective to identify areas for improvement. 
7. External audits were conducted by carefully selected external certification agency. The quality systems were certified during the external audit and the ISO 9001:2000 quality system certificates were issued.

8. The systems undergo continuous review and revisions are made when necessary as required by the certification requirements. The documentation remains under care of appointed individuals (documents guardians.)

The strategic reasons for implementing the quality management system in organizations generally vary. Some firms take decision to implement the quality management system because they plan to create an efficient and transparent system of management in organization. Others consider merely getting ISO 9001: 2000 certificate as a stand-alone strategic goal. The reasons of implementing quality management systems include gaining a sustainable competitive advantage, client requirements and cost reduction. Table 1 presents a comparison of the food processing facility and the University on selected dimensions relevant for quality system certification under ISO 9001:2000.

Table 1: Selected characteristics of a meat processing plant and a University

\begin{tabular}{|l|l|l|}
\hline Dimension & \multicolumn{1}{|c|}{ Meat Processing Facility } & \multicolumn{1}{c|}{ College at a University } \\
\hline Type of business & $\begin{array}{l}\text { Manufacturing and commercial } \\
\text { enterprise }\end{array}$ & Service, non-profit organization \\
\hline Ownership & Private & Public \\
\hline Business objective & Profit maximization & Non-profit, tax-exempt \\
\hline Hours of work and schedules & Rigid, based on shifts & Flexible, based on need \\
\hline Product & Tangible & Intangible, professional service \\
\hline Customer & The food products wholesaler & $\begin{array}{l}\text { Students, employers of students, society. } \\
\text { Attracts students nationwide }\end{array}$ \\
\hline Organizational structure & $\begin{array}{l}\text { Traditional organizational pyramid, } \\
\text { functional divisions }\end{array}$ & $\begin{array}{l}\text { Functional academic divisions with distinct } \\
\text { focus and substantial management autonomy } \\
\text { of the departments }\end{array}$ \\
\hline Time-frame & Calendar year (seasonal production) & $\begin{array}{l}\text { Academic year (seasonal offerings } \\
\text { characterized by peaks and valleys) }\end{array}$ \\
\hline Competition & Global, unlimited & $\begin{array}{l}\text { Limited geographically to public and private } \\
\text { schools with a similar profile of instruction }\end{array}$ \\
\hline Scope of activity & $\begin{array}{l}\text { Local and regional with wholly-owned } \\
\text { subdivisions scattered nationwide }\end{array}$ & $\begin{array}{l}\text { Central location, limited off-campus program } \\
\text { offerings, in-class instruction }\end{array}$ \\
\hline
\end{tabular}

In the food production plant the decision to implement the quality system based on ISO-9001:2000 was mandated by the legal requirement to implement the HACCP (Hazard Analysis and Critical Control Point) system. The barrier to fast implementation of the system was a lack of general process knowledge among operational level workers. This void was addressed by retaining the services of a consulting group with the goal of conducting employee training. A major reason for implementing the system was to demonstrate strategic commitment to quality and the process of continuous improvement. Substantial changes in internal business process according to the ISO 9001: 2000 standard followed. The goal was to promote systemic thinking across functional boundaries and the adoption of a process orientation. This approach was well received by the employees who often volunteered their time and expertise to assist with the project.

In the University the interest of implementing quality management system resulted from the lectures on quality management. The idea also generated broad support in the College constituents, including faculty, students and administration. The level of awareness of ISO 9001: 2000 and HACCP principle was sufficient to skip the general employee training phase. More focused training was offered that addressed the specifics (the how to?) rather that the strategic justification for and the benefits of certification (the why?). Focus teams were established from the faculty ranks that were charged with the task of preparing appropriate documentation (procedures and instructions). The main strategic similarity in implementing quality management system in the food production plant and at the University was a shared desire to improve internal business processes in order to achieve a sustainable competitive advantage in the market segments. The certification tasks were implemented by empowered teams consisting of faculty, 
administrators, support personnel and students. This broad involvement of many constituent groups facilitated the process of building consensus. It also provided students with a unique opportunity to get a hands-on experience in developing and implementing the system.

Internal system audits were performed by selected employees trained to perform the duties of internal auditors. In the food processing organization the group was formed by selecting workers from different units. The groups were led by experienced employees and were assisted by external consultants retained for this purpose. In the University the internal auditors were students and instructional employees. Students were trained to conduct audits for two reasons. They could apply their theoretical knowledge in practice. Then, knowing their expectations and difficulties as clients they helped to improve the effectiveness of the internal audits.

Both organizations have implemented their quality management systems using a process approach. In the food processing, the map of processes included four groups: primary, supporting, internal and external. The external processes involved a review of organizations in the supply chain as well as product distributors. At the University the external processes were not reviewed. A sample of processes documented under ISO 9001: 2000 quality system in the meat plant on the basis of information identified during the initial review is shown in Table 2.

Despite its disadvantages the decision was made by the management of both companies to prepare paper versions of quality management system documentation. This was necessitated by a lack of access to computer terminals on an as-need basis by all personnel involved in the processes that were being documented. It was determined that at the time implementing a comprehensive computer system to provide such access was too costly. After its computer system has been upgraded, the University has made a successful transition to electronic documentation in late 2004.

The legal requirements concerning the processes and activities determined the boundaries of both systems that the ISO 9001: 2000 documentation could not redefine. For the food processing plant these rules include the provisions of HACCP and the FDA rules. For the University the academic freedom tradition guarantees the organizational units significant autonomy in hiring, retention, recruitment, purchasing, etc. We note that some University departments use chemical and biological analysis and laboratory equipment. These departments derived significant benefits from the quality system certification.

\section{The System Maintenance and Improvement}

If used properly, the quality management system can be a useful tool in management of organizations. The characteristic of organization determines the nature and scope of the implementation and improvement of processes. In the meat production company the role of a customer is indirect. Customer satisfaction studies are performed periodically and the results are taken into account during the planning and production processes. Similar studies are conducted at the University. With students being the main customers for the education institution the questionnaires measure the students' satisfaction with the education process. Students are also directly involved in the improvement process by participating in internal system audits. There exist formal and informal channels involving students interested in the system quality management issues. These channels allow students to make recommendations to solve specific problems of and recommend solutions to it. Such discrepancies between expectations and reality are easy to define in the food industry because the data collected from processes adequately measure system performance. The discrepancy is usually caused by a lack of process capabilities and results in unmet product requirements. It is much harder to quantitatively define the discrepancies and their causes at the University due to the intangible nature of the educational service. We add that even the definition of a customer is fuzzy in the educational system setting. For example, one indicator of system quality is a ratio of application for admission received to the number of freshmen students admitted. Referring to the instructional process an indicator of system quality could be a ratio of pass grades to fail grades. 
Table 2: Processes documented in a food processing plant and a University

\begin{tabular}{|c|c|}
\hline Meat Processing Facility & College at a University \\
\hline $\begin{array}{l}\text { PRIMARY PROCESSES } \\
\text { Internal: } \\
\text { - Design of new and modification of existing products - } 1 \\
\text { procedure } \\
\text { - Pre-production activities (capacity, equipment, labor, } \\
\text { facilities) - } 1 \text { procedure } \\
\text { - Production activities (inventory policies, storage, } \\
\text { cleaning, scheduling) - } 1 \text { procedure } \\
\text { External: } \\
\text { - Developing and managing suppliers - } 2 \text { procedures } \\
\text { - Inbound and outbound transportation and logistics - } 1 \\
\text { procedure }\end{array}$ & $\begin{array}{l}\text { PRIMARY PROCESSES } \\
\text { - Curricular design and modification - } 5 \text { procedures, } 15 \\
\text { instructions } \\
\text { - Student recruitment }-1 \text { procedure } \\
\text { - Instruction (including resource management) - } 8 \\
\text { procedures, } 6 \text { instructions }\end{array}$ \\
\hline $\begin{array}{l}\text { SUPPORTING PROCESS } \\
\text { - Management processes - } 11 \text { procedures, including } \\
\circ \text { Management responsibility: } 7 \text { procedures } \\
\circ \text { Training and development, recruitment, retention, } \\
\text { compensation - } 4 \text { procedures } \\
\text { - Veterinary supervision - no procedures. The list of } \\
\text { contacts and references to external sources were needed. } \\
\text { - Government rules and regulations - no procedures. The } \\
\text { list of contacts and references to external sources were } \\
\text { needed. }\end{array}$ & $\begin{array}{l}\text { SUPPORTING PROCESS } \\
\text { - Graduation requirements }-1 \text { procedure } \\
\text { - Awarding a University degree }-1 \text { procedure } \\
\text { - University administration }-6 \text { procedures, } 12 \\
\text { instructions } \\
\text { - Continuous improvement and assurance of quality } \\
\text { (including data collection and analysis) - } 7 \text { procedures }\end{array}$ \\
\hline
\end{tabular}

The key similarities we identified regarding the requirements of the quality management system in a food processing plant and the University include: (i) preparing the map of processes, (ii) defining of the entry and exit points and key data requirements for specific procedures, (iii) preparing system documentation, (iv) methodically conducting internal audits involving all employees, and (v) top management documentation review.

The similarities in the implementation phase include (i) clear assignment of responsibility for development of system elements (ii) reference to the external legal framework, and (iii) emphasis on cross-functional orientation and improving communication and information flow. Table 3 summarizes the differences in developing and implementing a quality management system is both types of organizations.

Table 3: Criteria For Developing And Implementing A Quality Management System In A Meat Processing Plant And A University.

\begin{tabular}{|c|c|c|}
\hline Criterion & Meat Processing Facility & College at a University \\
\hline $\begin{array}{l}\text { Decision about implementing the } \\
\text { system }\end{array}$ & $\begin{array}{l}\text { Results from HACCP requirements } \\
\text { (indirect) }\end{array}$ & $\begin{array}{l}\text { Originates with University faculty } \\
\text { (direct) }\end{array}$ \\
\hline The use of external consultants & Yes & No \\
\hline $\begin{array}{l}\text { Direct responsibility of the } \\
\text { implementation and maintaining of the } \\
\text { system rests with }\end{array}$ & ISO 9001 management representative & $\begin{array}{l}\text { ISO } 9001 \text { representative, } \\
\text { documentation specialists and ISO } \\
\text { focus groups }\end{array}$ \\
\hline $\begin{array}{l}\text { Customer participation in system } \\
\text { implementation }\end{array}$ & No & Yes \\
\hline Initial certification need determination & Yes & No \\
\hline Documentation structure & $\begin{array}{l}\text { Project orientation with focus on } \\
\text { individual processes }\end{array}$ & $\begin{array}{l}\text { Neural network orientation with focus } \\
\text { on clusters of similar documents }\end{array}$ \\
\hline $\begin{array}{l}\text { Customer involvement in process } \\
\text { improvements }\end{array}$ & Indirect & Direct \\
\hline
\end{tabular}




\section{CONCLUSIONS}

In this paper we presented the strategic framework for ISO 9001:2000 quality system development and certification. We observed that the certification process should be strategically justified in order to maximize the likelihood of success in the market, generate commitment of many key constituents and secure the resources needed for the project implementation and maintenance. We noted that the system implementation should improve organizational performance on selected key performance measures important to the customers. We also discussed key system implementation issues in production and service environments using a food processing plant and a University as illustrative examples.

\section{NOTES}


NOTES 